\title{
High activity CAZyme cassette for improving biomass degradation in thermophiles
}

Roman Brunecky ${ }^{1}$ Daehwan Chung ${ }^{1}$, Nicholas S. Sarai ${ }^{1}$, Neal Hengge ${ }^{1}$, Jordan F. Russell ${ }^{2}$, Jenna Young ${ }^{2}$, Ashutosh Mittal ${ }^{1}$, Patthra Pason ${ }^{3}$, Todd Vander Wall', William Michener ${ }^{1}$, Todd Shollenberger ${ }^{1}$, Janet Westpheling ${ }^{2}$, Michael E. Himmel ${ }^{1}$ and Yannick J. Bomble ${ }^{1 *}$ (i)

\begin{abstract}
Background: Thermophilic microorganisms and their enzymes offer several advantages for industrial application over their mesophilic counterparts. For example, a hyperthermophilic anaerobe, Caldicellulosiruptor bescii, was recently isolated from hot springs in Kamchatka, Siberia, and shown to have very high cellulolytic activity. Additionally, it is one of a few microorganisms being considered as viable candidates for consolidated bioprocessing applications. Moreover, C. bescii is capable of deconstructing plant biomass without enzymatic or chemical pretreatment. This ability is accomplished by the production and secretion of free, multi-modular and multi-functional enzymes, one of which, CbCel9A/Cel48A also known as CelA, is able to outperform enzymes found in commercial enzyme preparations. Furthermore, the complete C. bescii exoproteome is extremely thermostable and highly active at elevated temperatures, unlike commercial fungal cellulases. Therefore, understanding the functional diversity of enzymes in the $C$. bescii exoproteome and how inter-molecular synergy between them confers C. bescii with its high cellulolytic activity is an important endeavor to enable the production of more efficient biomass degrading enzyme formulations and in turn, better cellulolytic industrial microorganisms.

Results: To advance the understanding of the C. bescii exoproteome we have expressed, purified, and tested four of the primary enzymes found in the exoproteome and we have found that the combination of three or four of the most highly expressed enzymes exhibit synergistic activity. We also demonstrated that discrete combinations of these enzymes mimic and even improve upon the activity of the whole C. bescii exoproteome, even though some of the enzymes lack significant activity on their own.
\end{abstract}

Conclusions: We have demonstrated that it is possible to replicate the cellulolytic activity of the native C. bescii exoproteome utilizing a minimal gene set, and that these minimal gene sets are more active than the whole exoproteome. In the future, this may lead to more simplified and efficient cellulolytic enzyme preparations or yield improvements when these enzymes are expressed in microorganisms engineered for consolidated bioprocessing.

Keywords: Biofuels, Biomass degrading enzymes, Cellulose, Biomass, Thermophile, Caldicellulosiruptor bescii, Anaerobe

\footnotetext{
*Correspondence: Yannick.bomble@nrel.gov

1 Biosciences Center, National Renewable Energy Laboratory, 15013

Denver West Parkway, Golden, CO 80401, USA

Full list of author information is available at the end of the article
} 


\section{Background}

Caldicellulosiruptor bescii, the most thermophilic cellulolytic bacterium yet discovered, exhibits high cellulolytic activity on a variety of biomass substrates. It is able to grow on and deconstruct biomass without conventional pretreatments $[1,2]$. The carbohydrate-active enzymes (CAZymes) that $C$. bescii uses for biomass deconstruction are different from those used by other bacteria and fungi [3]. Nature has evolved cellulolytic microbes that produce a wide variety of enzymes that act on plant biomass using diverse deconstruction mechanisms. For example, Clostridium thermocellum relies on cellulosomes, which are complex protein assemblies attached to the microbial cell to mediate solubilization of plant biomass [4, 5]. However, this deconstruction mechanism is rare and only found in a few anaerobic bacteria and fungi. Most fungi and cellulolytic bacteria produce free enzymes that act synergistically $[6,7]$. This system represents the most common deconstruction mechanism for plant biomass in the biosphere [8]. On the other hand, C. bescii, like many other Caldicellulosiruptor species, relies primarily on a combination of CAZymes comprised of several catalytic domains instead of the canonical single catalytic domain architecture employed by other cellulolytic microorganisms. The $C$. bescii genome contains 88 CAZyme genes with varying degrees of complexity in their architectures, but the most abundant CAZymes in its exoproteome are multi-modular and multi-functional [9]. Cellulolytic ability correlates with the presence of CelA (CbCel9A/ Cel48A) the most abundant CAZyme in the $C$. bescii exoproteome. CelA consists of a Family $9 \mathrm{~A}-\mathrm{CBM} 3_{\mathrm{c}}$ processive endoglucanase, a Family 48 exoglucanase, and two Family $3 \mathrm{~b}$ carbohydrate-binding modules $\left(\mathrm{CBM} 3_{\mathrm{b}}\right)$ connected by proline/threonine rich linker regions $[10,11]$. $\mathrm{CbCel9A} / \mathrm{Cel} 48 \mathrm{~A}$ is so far the most efficient single gene product ever tested for biomass deconstruction and has been shown to be vital for $C$. bescii growth on plant biomass [12]. $\mathrm{CbCel9A/Cel48A}$ represents nearly $50 \%$ of the CAZymes in the exoproteome [13], yet there remains a significant fraction of other multi-modular and multifunctional CAZymes. It is becoming clear that the high cellulolytic activity displayed by this system is the result of inter-molecular synergy between these CAZymes [14].

The next three most abundant CAZymes in the exo-

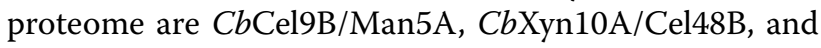
CbMan5B/Cel44A, respectively. CbCel9B/Man5A has an $\mathrm{N}$-terminus $\mathrm{GH} 9$ catalytic domain linked to a CBM3 module, a construct similar to that of the $\mathrm{N}$-terminus of $\mathrm{CbCel} 9 \mathrm{~A} / \mathrm{Cel} 48 \mathrm{~A}$, which is also likely to be active on cellulose, as well as two $\mathrm{CBM}_{\mathrm{b}}$ modules and a GH5

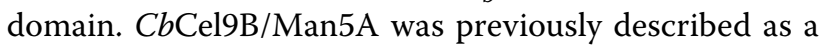
mannanase [15]. CbXyn10A/Cel48B contains two catalytic domains, a GH10 and a GH48; as well as two $\mathrm{CBM}_{\mathrm{b}}$ modules suggesting it is a xylanase and a processive cellulase. Finally, CbMan5B/Cel44A is comprised of a GH5, a $\mathrm{GH} 44$, and two $\mathrm{CBM}_{\mathrm{b}}$ modules, which suggests that it is a bifunctional mannanase/endoglucanase or possibly a xyloglucanase. Understanding the synergy between these enzymes during biomass deconstruction is vital to achieving our goal of enhanced understanding of biomass deconstruction in the biosphere including how microorganisms have evolved different sets of CAZymes to efficiently degrade biomass. Furthermore, a deeper understanding is also important to enable the development of thermophilic CAZyme cassettes which may be used in large scale biomass saccharification applications, such as biofuels production. Another nascent application of such cassettes of cell wall degrading enzymes will enable promising non-cellulolytic thermophiles, already producing high titers of biochemical products, to deconstruct biomass within a consolidated bioprocessing (CBP) strategy. Indeed, biomass deconstruction at elevated temperatures presents several advantages in simultaneous saccharification and fermentation (SSF) as well as CBP applications. Thermophilic conditions can allow better enzyme penetration and cell-wall disorganization of the biomass, thermostable enzymes are often more resistant to the relatively harsh conditions of industrial processes with high solvent or high salt concentrations and offer potentially faster reaction kinetics [16-18]. Perhaps most importantly, high temperatures in a fermentative process prevent costly microbial contamination [16-18]. In this study, we show that these thermostable enzymes from $C$. bescii possess strong synergy and that the performance of certain combinations of these enzymes is competitive with that of the entire exoproteome. We suggest that a CAZyme cassette including three or four of these enzymes is enough to recapitulate and even exceed the activity of the $C$. bescii exoproteome, showing they are ideal candidates to confer the ability to degrade cellulosic substrates effectively to non-cellulolytic thermophiles.

\section{Results and discussions \\ Homologous expression and the purification of CbCel9A/Cel48A, CbCel9B/Man5A, CbXyn10A/Cel48B, and $\mathrm{CbMan} 5 \mathrm{~B} / \mathrm{Cel} 44 \mathrm{~A}$}

To investigate the synergy between four extracellular CAZymes from $C$. bescii, we homologously expressed and purified $C b C e l 9 A / C e l 48 A$ (Cbes_1867), CbCel9B/ Man5A (Cbes_1865), CbXyn10A/Cel48B (Cbes_1857), and CbMan5B/Cel44A (Cbes_1859) (Fig. 1). Expression of these thermophilic extracellular proteins in their native host with correct post-translational modification, in this case glycosylation, is essential to retain native activity and stability, especially at the elevated optimal growth temperature of $C$. bescii. Extensive studies have been 

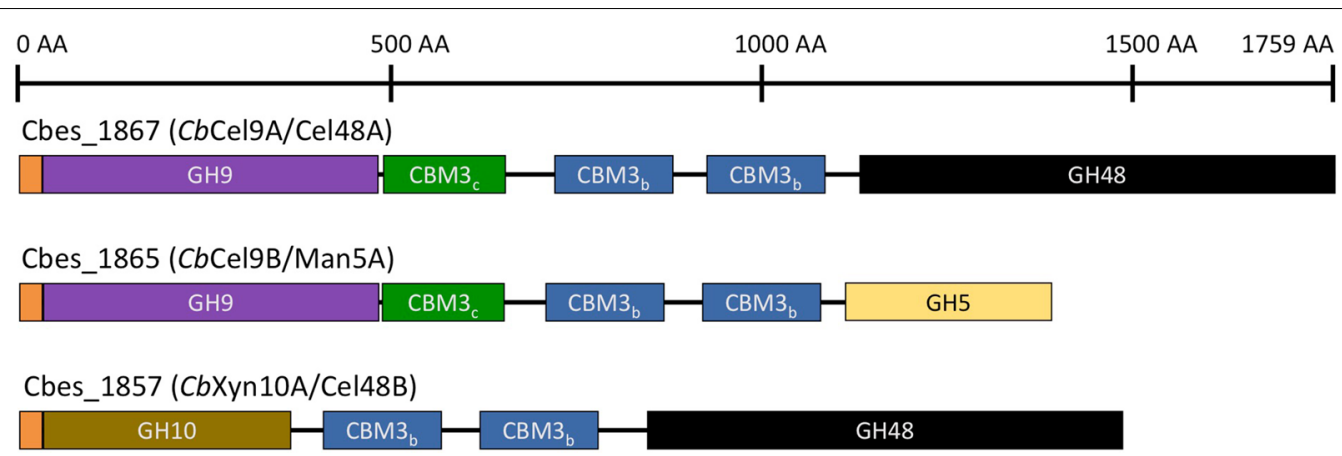

Cbes_1859 (CbMan5B/Cel44A)

$\mathrm{GH} 5$

Fig. 1 Domain organization of multifunctional CAZymes from the exoproteome of C. bescii. CelA, the dominant CAZyme in the exoproteome of $C$. bescii and three additional multifunctional enzymes were homologously expressed. Each enzyme contains two catalytic domains and two or three family 3 carbohydrate binding modules separated by proline/threonine rich linker peptides

performed to biochemically characterize these four pro-

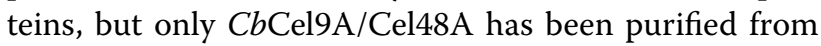
its native host [10]. Previous studies for the other three most abundant CAZymes in the exoproteome, $\mathrm{CbCel9B/}$ Man5A, CbXyn10A/Cel48B, and CbMan5B/Cel44A, utilized proteins expressed in $E$. coli at mesophilic temperature, thus potentially lacking proper post-translational modifications [15, 19-22]. Additionally, all but one of these studies focused only on a catalytic domain from these CAZymes.

To address these issues, we constructed three new expression vectors (Fig. 2) and C. bescii expression strains (Additional file 1: Table S1). Diagrams of the domain architecture of four CAZymes employed in this study are shown in Fig. 1, with $\mathrm{CbCel9A/Cel48A} \mathrm{being}$ from Chung et al. [23]. These polypeptides contain predicted signal peptides, catalytic domains, and CBMs. Expression vectors were constructed by inserting the gene encoding Cbes_1857, Cbes_1859, and Cbes_1865 into pDCW173, resulting in pJYW011, pJYW012, and pJYW013, respectively (Fig. 2). pDCW173 contains an expression cassette for $\mathrm{CbCel} 9 \mathrm{~A} / \mathrm{Cel} 48 \mathrm{~A}$ and was successfully used to homologously express CelA [10, 23]. The $C b C e l 9 \mathrm{~A} / \mathrm{Cel} 48 \mathrm{~A}$ expression cassette directs transcription of $C b C$ el9A/Cel48A using the regulatory and rho independent terminator sequences surrounding Cbes_2303 (S-layer protein) and contains a C-terminal 6X histidine-tag (Fig. 1a), followed by a stop codon. We replaced the Cbes_1867 gene by other multifunctional coding genes to create pJYW011, pJYW012, and pJYW013. Plasmid DNA was transformed into JWCB029 (SpyrFA $\triangle l d h:: I S C b e 4 \Delta c b e 1 \Delta c e l A)$ [12] and transformants were selected for uracil prototrophy. The presence of the plasmid in transformants was confirmed by PCR amplification using extracted total DNA as template.
Primers (DC228 and DC569) were used to amplify the portion of the plasmid containing the open reading frame of Cbes_1867, Cbes_1857, Cbes_1859, and Cbes_1865. PCR amplified products confirmed the presence of each CAZyme encoding gene within its plasmid (data not shown). The structural stability and maintenance of plasmids in expression strains were assessed by back-transformation of total DNA isolated from four independent C. bescii transformants into $E$. coli as described in Chung et al. [27] (data not shown). The SDS-PAGE result in Additional file 1: Figure S1 clearly shows that all protein constructs were successfully expressed, secreted, and purified to homogeneity. We did not detect any significant proteolytic cleavage products or prematurely terminated products, which often occur during expression and purification from E. coli (data not shown). The predicted sizes of the proteins, Cbes_1867 ( $195 \mathrm{kDa})$, Cbes_1857 $(\sim 165 \mathrm{kDa})$, Cbes_1859 ( $142 \mathrm{kDa})$, and Cbes_1865 $(\sim 151 \mathrm{kDa})$ were in accordance with these SDS-PAGE results.

\section{Substrate specificity and product profiles of $\mathrm{CbCel9A} /$ Cel48A, CbCel9B/Man5A, CbXyn10A/Cel48B, and $C b$ Man5B/Cel44A}

Although we have already characterized $C b C e l 9 \mathrm{~A} / \mathrm{Cel} 48 \mathrm{~A}$ extensively in other publications $[10,11]$, additional substrate specificity data for this enzyme is included here for completeness. Based on biochemical assays using $p$-nitrophenyl $(p \mathrm{NP})$ and azurine cross-linked-labeled (AZCL) derivatives, we identified CbXyn10A/Cel48B as possessing primarily xylanase activity with some minimal cellulase activity most likely conferred by the GH48 module. One should note that the GH48 of $\mathrm{CbCel9A/Cel48A}$ was also shown to exhibit strong xylanase activity [10]. Activity on galactose and glucose are also possible side 


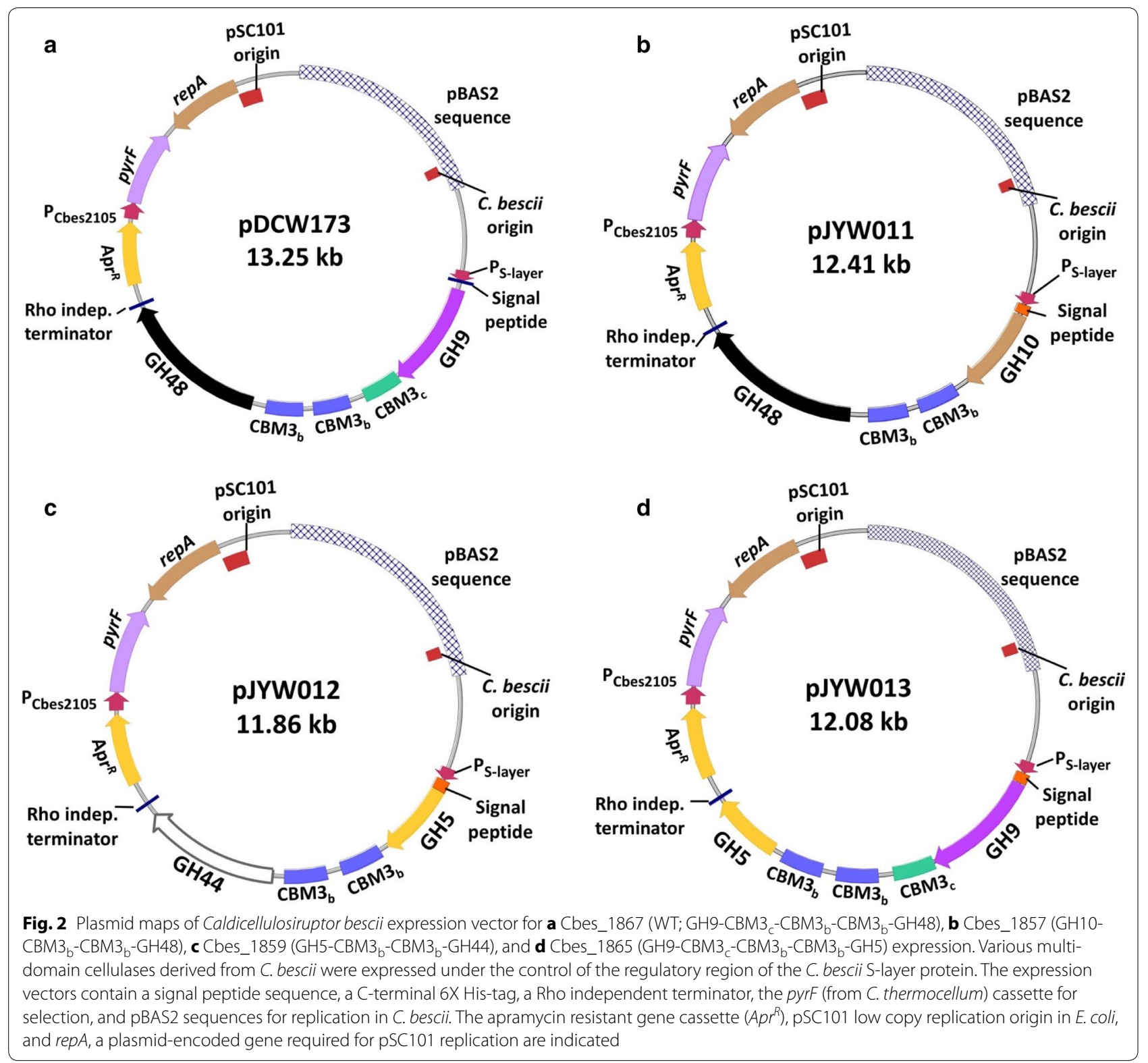

activities (Fig. 3; Additional file 1: Figure S2). CbCel9A/ Man5A is primarily identified as a mannanase based on the high activity on $p$ NP-mannose and AZCL-mannan, with residual activity on cellulose and xylan. Finally, $\mathrm{CbMan} 5 \mathrm{~B} / \mathrm{Cel} 44 \mathrm{~A}$ is also primarily classified as a mannanase, due to its activity on $p \mathrm{NP}$-mannan and AZCLmannan, along with secondary activities as a xylanase and cellulase. The Cel44A module is likely a xyloglucanase as indicated by the AZCL xyloglucanase activity detected.

Single product activity profiles were generated after digesting alkaline peroxide pretreated corn stover (APCS) [11]. The primary products for $\mathrm{CbCel9A} / \mathrm{Cel} 48 \mathrm{~A}$ were glucose and cellobiose in a 1:2.5 ratio with a trace of cellotriose also detected (Additional file 1: Figure S3). For the xylanase, CbXyn10A/Cel48B, the primary cello oligomer detected was cellobiose, with very little glucose and cellotriose (Additional file 1: Figure S3). For $\mathrm{CbCel9B/Man5A}$ only glucose and cellobiose were detected in a 1:2.2 ratio (Additional file 1: Figure S3). CbMan5B/Cel44A has low overall activity on glucan, with cellobiose being the primary product, but with both glucose and cellotriose appearing in an approximate 2:1 ratio relative to cellobiose. There was also a trace of cellotetraose detected for $\mathrm{CbMan} 5 \mathrm{~B} / \mathrm{Cel} 44 \mathrm{~A}$ in a $6: 1 \mathrm{cel}-$ lobiose/cellotetraose ratio (Additional file 1: Figure S3). The enzymes were also analyzed for xylan release profiles, however, no attempt was made to quantify release. 

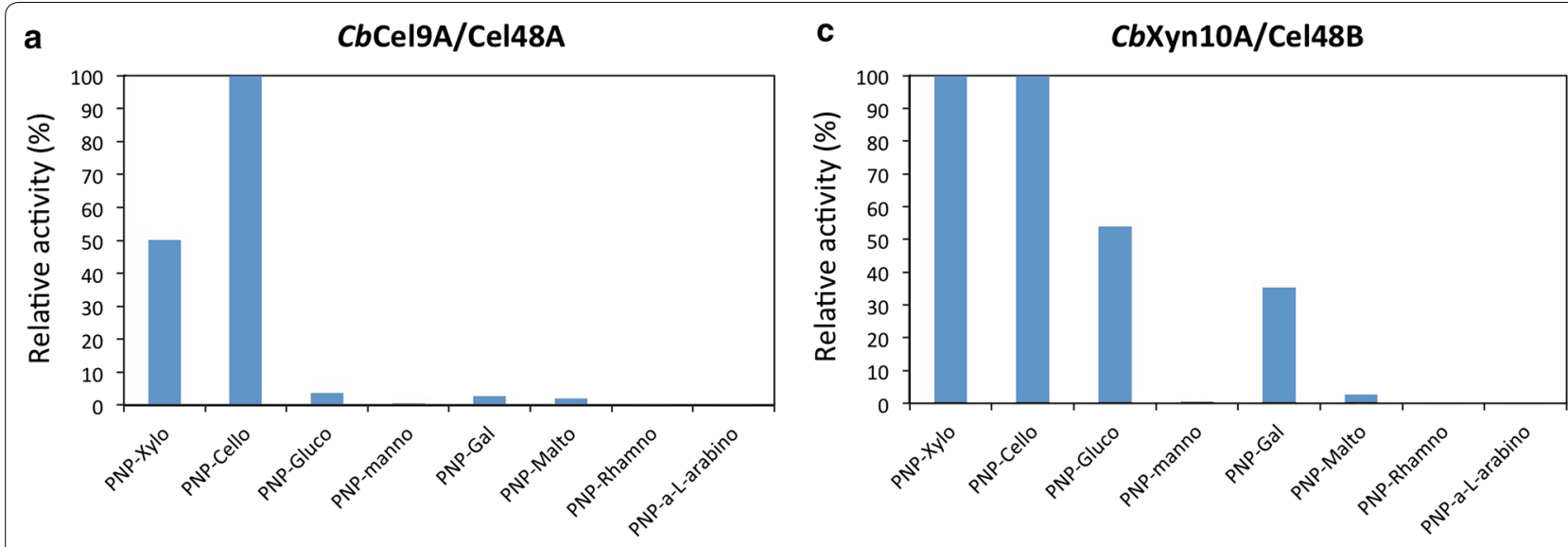

b

CbCel9B/Man5A

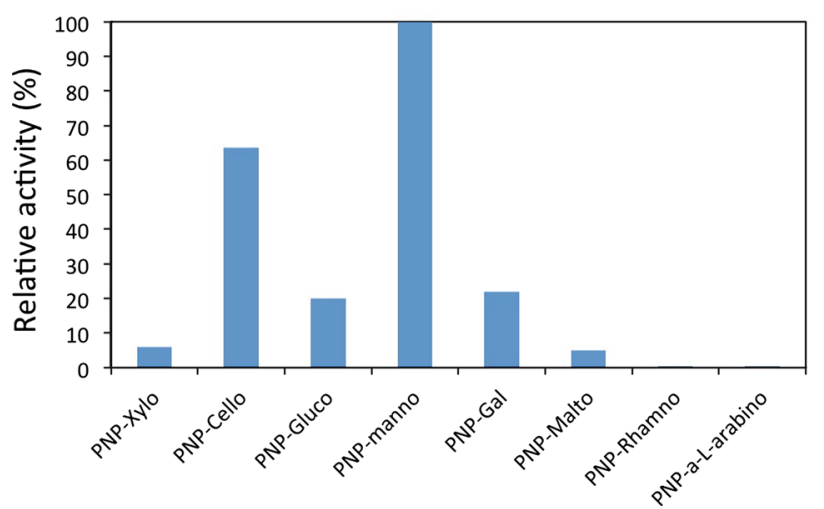

d

CbMan5B/Cel44A

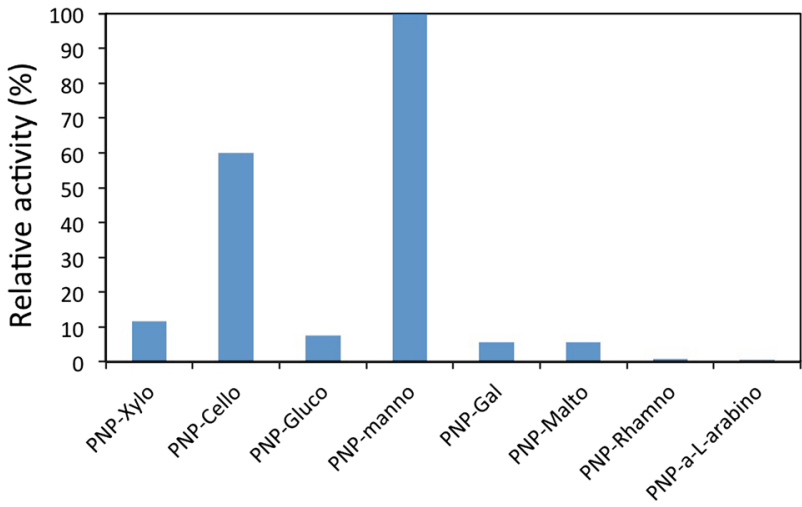

Fig. 3 Substrate specificity of CbCel9A/Cel48A, CbCel9B/Man5A, CbXyn10A/Cel48B, and CbMan5B/Cel44A. Relative activity with respect to optimal activity of, a CbCel9A/Cel48A, b CbCel9B/Man5A, c CbXyn10A/Cel48B, d CbMan5B/Cel44A, on various PNP substrates as noted

All enzymes, except $C b C$ el9A/Cel48A, produced xylooligomers up to DP7, whereas $\mathrm{CbCel9A/Cel48A} \mathrm{produces}$ xylooligomers up to DP6 (Additional file 1: Table S3).

\section{Effect of $\mathrm{pH}$ and temperature on the activity of $\mathrm{CbCel9A} /$ Cel48A, CbCel9B/Man5A, CbXyn10A/Cel48B, and $C b M a n 5 B / C e l 44 A$}

Biomass digestion experiments with the single enzymes and the $C$. bescii exoproteome over a range of temperatures $\left(70-90{ }^{\circ} \mathrm{C}\right)$ and $\mathrm{pH}(4.0-7.0)$ were carried out on APCS to determine relative activity within these $\mathrm{pH}$ and temperature ranges. The optimal temperature for enzyme performance was found to be $85^{\circ} \mathrm{C}$ for the $\mathrm{C}$. bescii exoproteome, $C b C e l 9 A / C e l 48 \mathrm{~A}, C b X y n 10 \mathrm{~A} / \mathrm{Cel} 48 \mathrm{~B}$, and CbCel9B/Man5A while CbMan5B/Cel44A showed a lower optimal temperature in the range of $\left(75-80{ }^{\circ} \mathrm{C}\right)$ (Fig. 4). These results are similar to previous reports for $\mathrm{CbCel9A} / \mathrm{Cel} 48 \mathrm{~A}$ on Avicel [10]. Even at elevated temperatures e.g., $90{ }^{\circ} \mathrm{C}$, the single enzymes as well as the $C$. bescii exoproteome showed relative activity greater than $60 \%$. All single enzymes and the $C$. bescii exoproteome appear to have the highest activity in the $\mathrm{pH}$ range of 5-5.5 (Fig. 4), within the range of $\mathrm{pH}$ reported to be optimal for $C$. bescii CAZymes, $C b C e l 9 A / C e l 48 A$ and $C$. bescii exoproteome being commonly used at $\mathrm{pH} 5.5[10$, 11, 23-25].

\section{Enzyme performance on pretreated biomass}

Single enzyme performance was evaluated at an equal enzyme loading using APCS. CbCel9A/Cel48A, as shown in previous report $[10,11]$, exhibits high activity on glucan and is the most active enzyme of the set on this biomass substrate component (Fig. 5a). The other enzymes are not as active on glucan with barely $10 \%$ conversion compared to close to $60 \%$ for $\mathrm{CbCel} 9 \mathrm{~A} /$ Cel48A. CbCel9A/Cel48A also showed the ability to efficiently deconstruct xylan and was the second most active enzyme on this component, with CbXyn10A/Cel48B being clearly and logically, given its makeup, the best performer on xylan (Fig. 5b). We observed more xylan conversion with $\mathrm{CbCel}$ 19B/Man5A and $C b \mathrm{Man} 5 \mathrm{~B} / \mathrm{Cel} 44 \mathrm{~A}$ than expected from the preliminary $p \mathrm{NP}$ and $\mathrm{AZCL}$ 

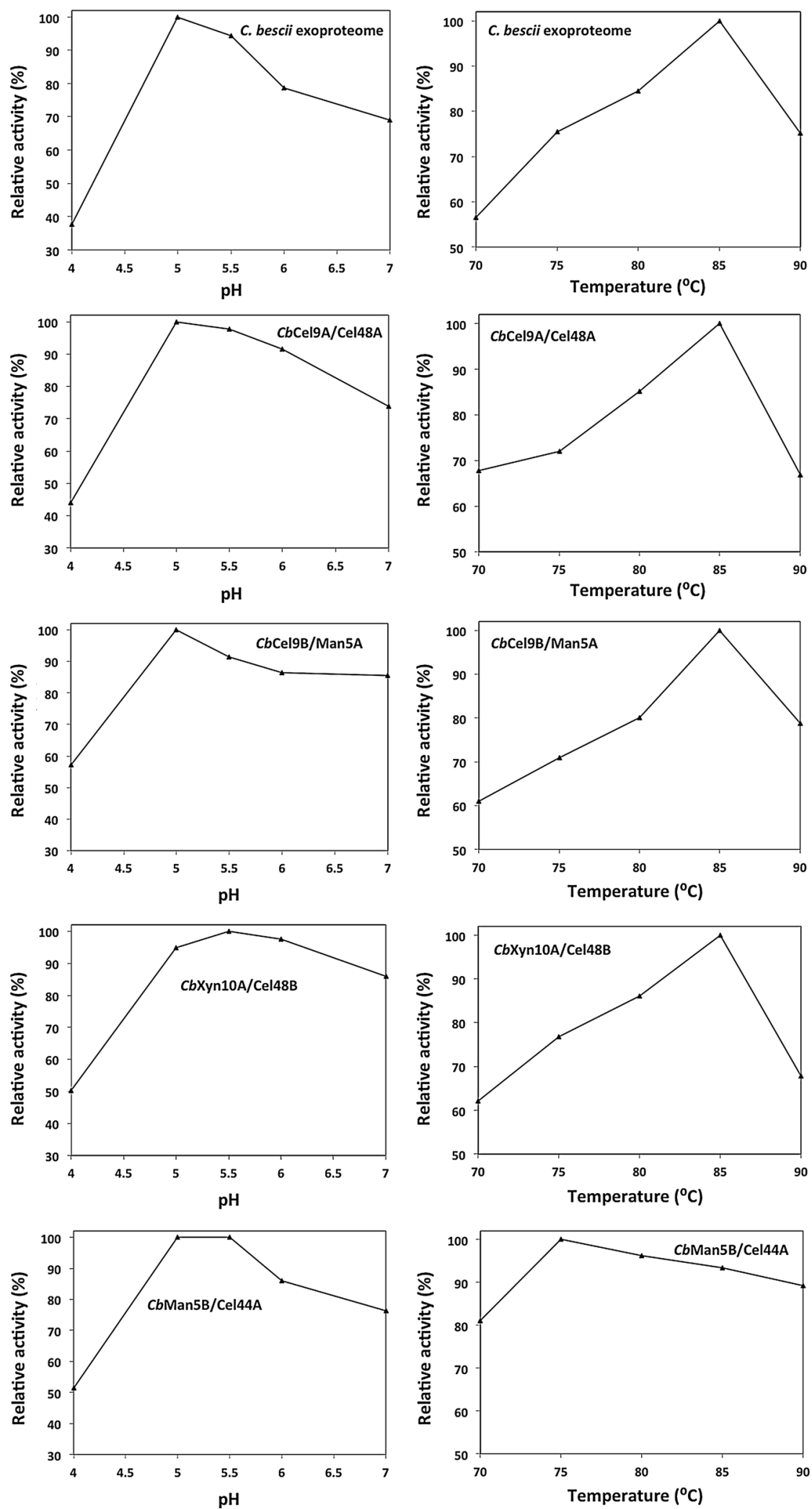

Fig. 4 Effect of pH and temperature on the activity of CbCel9A/Cel48A, CbCel9B/Man5A, CbXyn10A/Cel48B, and CbMan5B/Cel44A on APCS. Relative activity remaining with respect to optimal activity for the four CAZymes and the C. bescii exoproteome at different pH (4.0-7.0) and temperatures $\left(70-90^{\circ} \mathrm{C}\right)$ on the substrate APCS 

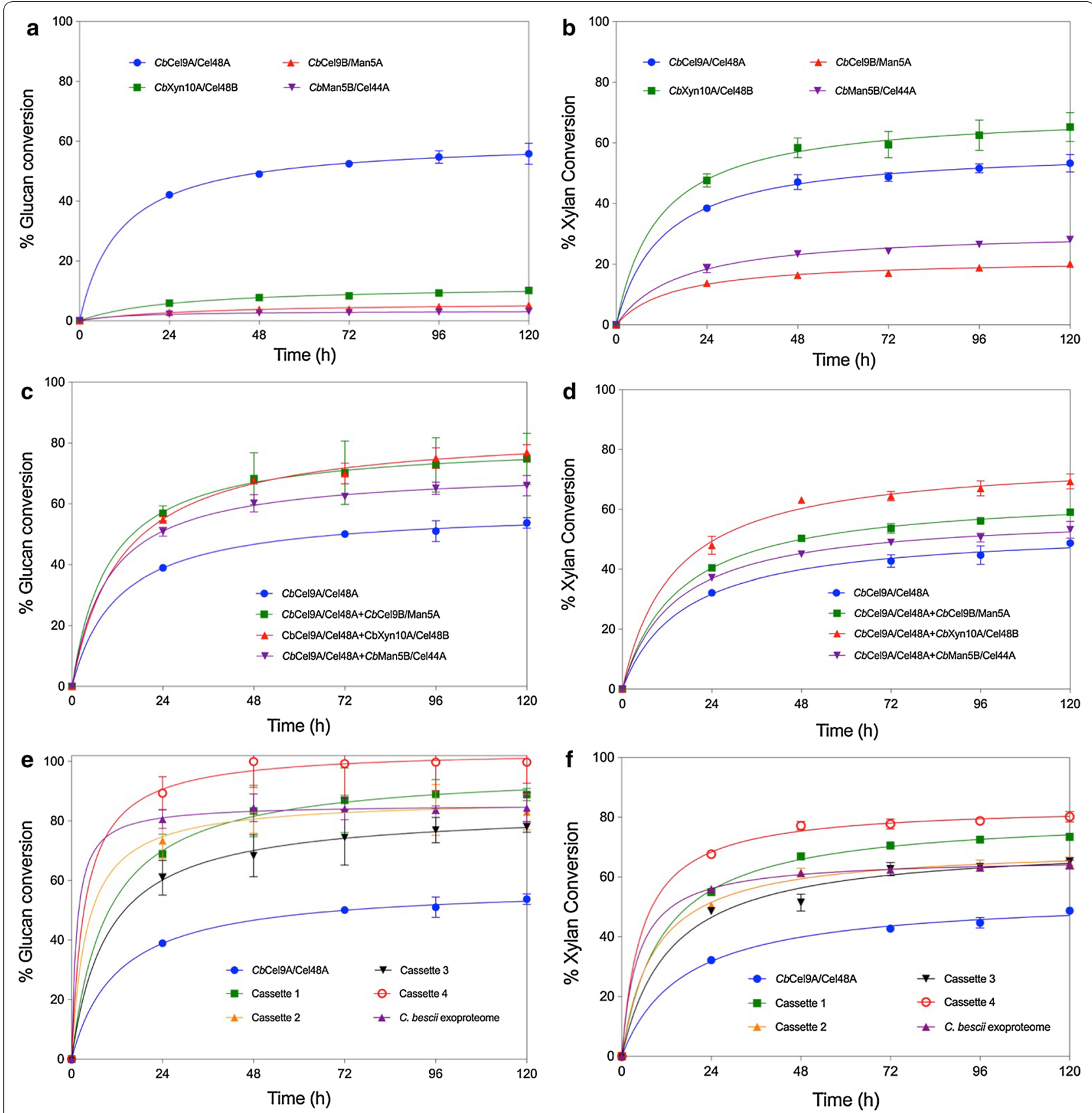

Fig. 5 APCS conversion by CbCel9A/Cel48A, CbCel9B/Man5A, CbXyn10A/Cel48B, and CbMan5B/Cel44A. a Glucan conversion of APCS by individual C. bescii enzymes, $\mathbf{b}$ xylan conversion of APCS by individual C. bescii enzymes, $\mathbf{c}$ glucan conversion of APCS by binary combinations of $C$. bescii enzymes, $\mathbf{d}$ xylan conversion of APCS by binary combinations of C. bescii enzymes, e glucan conversion of APCS by ternary and quaternary combinations of $C$. bescii enzymes, $\mathbf{f}$ Xylan conversion of APCS by ternary and quaternary combinations of $C$. bescii enzymes. Cassette 1 is a combination of CbCel9A/Cel48A, CbCel9B/Man5A, CbXyn10A/Cel48B, cassette 2 is a combination of CbCel9A/Cel48A, CbCel9B/Man5A, CbMan5B/Cel44A, cassette 3 is a combination of CbCel9A/Cel48A, CbXyn10A/Cel48B, CbMan5B/Cel44A, cassette 4 is a combination of CbCel9A/Cel48A, CbCel9B/Man5A, CbXyn10A/Cel48B, CbMan5B/Cel44A. All enzyme loadings can be found in the methods section and supplementary information (Additional file 1: Tables S4, S5)

assays. This may be due to the fact that the synthetic pNP substrates may not always fit well into the active sites of enzymes and is a known limitation of the pNP assay in general. Moreover, single enzyme analysis suggests that $\mathrm{CbCel9A} / \mathrm{Cel} 48 \mathrm{~A}$ is the major enzyme in the C. bescii exoproteome. Given the low glucan conversion 
rate demonstrated by $\mathrm{CbCel} 9 \mathrm{~B} / \mathrm{Man} 5 \mathrm{~A}$, we conclude that this enzyme acts on glucan similar to a traditional endo pair with low specific rates when compared to processive enzymes. CbXyn10A/Cel48B appears to be the major xylan degrading enzyme in the $C$. bescii exoproteome based on the fact that it converts xylan at a slightly higher rate than $C b C e l 9 A / C e l 48 \mathrm{~A}$ (65 and 55\%, respectively). $\mathrm{CbMan} 5 \mathrm{~B} / \mathrm{Cel} 44 \mathrm{~A}$ is likely to be a bi-functional nonprocessive endo type of enzyme. Interestingly all of the $C$. bescii CAZymes have activity on xylan even though they are not in all cases comprised of glycoside hydrolases with obvious xylanase activity.

\section{Synergism between $\mathrm{CbCel9A/Cel48A}$ and multiple CAZymes, comparison to the exoproteome: the making of an efficient and tractable CAZyme cassette}

We developed these digestion experiments and selected enzyme loadings using the ratios in which these CAZymes occur in the $C$. bescii exoproteome (Additional file 1: Tables S4, S5). As stated above, CbCel9A/Cel48A is the major biomass active enzyme present in the exoproteome; when combined with either $\mathrm{CbCel9B/Man} 5 \mathrm{~A}$ or $C b X y n 10 \mathrm{~A} / \mathrm{Cel} 48 \mathrm{~B}$ we observe a synergistic increase in activity from about $50-80 \%$ in glucan conversion on APCS (Fig. 5c). Again, these digestion experiments were conducted at the same enzyme ratios as in the exoproteome [13]. We observed that when multiple enzymes are added, rapid hydrolysis of the substrate occurs (see Fig. 5e) and we could thus recapitulate the extent of digestion achieved by the whole exoproteome with the addition to $\mathrm{CbCel} 9 \mathrm{~A} / \mathrm{Cel} 48 \mathrm{~A}$ of $\mathrm{CbCel} 9 \mathrm{~B} / \mathrm{Man} 5 \mathrm{~A}$ and CbXyn10A/Cel48B or $\mathrm{CbCel9B/Man5A}$ and CbMan5B/ Cel44A. Ultimately if all four CAZymes are used together (including $\mathrm{CbCel9A} / \mathrm{Cel} 48 \mathrm{~A}$ ) this quaternary CAZyme cassette can rapidly convert all of the substrate present to an even greater extent than the native exoproteome (Fig. 5e). This is likely due to a higher loading of active components when compared to the whole exoproteome, which likely contains other non-biomass active enzymes such as proteases and other enzymes even though we know that these are in low abundance from proteomic analyses [13]. This quaternary CAZyme cassette could also be exploited to deal with a wide variety of natural substrates by modifying the ratio of each CAZyme present. In our experiments we attempted to replicate the natural ratios of enzymes present in the whole $C$. bescii exproteome when grown on a crystalline substrate as described by Lochner et al., however, when dealing with different natural substrates the composition of the exproteome is likely different [13]. Nevertheless, we would expect similar improvements could be realized on native substrates by altering enzyme ratios.
Xylan conversion follows a somewhat similar pattern to that found for glucan conversion-addition of any single enzyme improves the overall extent of conversion when compared to CbCel9A/Cel48A alone. The best addition, unsurprisingly, utilizes the $\mathrm{CbXyn} 10 \mathrm{~A} / \mathrm{Cel} 48 \mathrm{~B}$ xylanase (Fig. 5d). However, given that this enzyme is even more active on xylan than CbCel9A/Cel48A this effect is not as pronounced. Addition of multiple enzymes again results in the rapid conversion of xylan and addition of any two components equals the performance of the whole exoproteome (Fig. 5f). Similar to the glucan conversion results, cassette 1 with three enzymes or cassette 4 with all four enzymes show dramatically improved performance when compared to the exoproteome (Fig. 5f). It should be noted that while the conversion of glucan by cassette 4 reached $100 \%$, the conversion of xylan reached $80 \%$ at the $120 \mathrm{~h}$ time point, but given that the whole exoproteome reached only $60 \%$ conversion in the same amount of time a likely explanation is that end product inhibition is occurring for the xylan degrading enzymes as there is a significant amount of xylobiose present at the end of the digestion and the addition of a thermostable $\beta$-xylosidase would likely further improve the performance of cassette 4. Furthermore, when considering the CAZyme cassette and the natural exoproteome in the broader context of life in a hot springs the uptake of sugars by the organism itself and rapid diffusion at high temperatures would keep end product inhibition to a minimum. Alternatively, in nature, there may also be other thermophilic enzymes present in a hot springs pool that may have thermostable $\beta$-xylosidase enzymes that would further enhance the degradation of plant biomass.

These findings, when combined with our previous work demonstrating that the addition of the endoglucanase AcCel5A from Acidothermus cellulolyticus dramatically improves the activity of the whole exoproteome, makes our outlook to engineer more active CAZyme cassettes very promising [24].

\section{Conclusions}

The C. bescii proteome is a rich source of highly active hyperthermophilic enzymes. Individually, $C b C \mathrm{Cl} 9 \mathrm{~A} /$ Cel48A is by far the most active enzyme in the exoproteome on glucan and the second most active on xylan. The next most abundantly expressed enzymes have marginal activity on glucan but significant activity on xylan and mannan. Interestingly, these enzymes show high degrees of synergy in the deconstruction of glucan from biomass. This natural condition of C. bescii may signal the reality of life in hot springs, where the likelihood of an array of other lignocellulolytic species to reduce the burden of enzyme production is diminished. 
Indeed, by tailoring an enzyme cassette with four enzymes we were able to achieve a higher extent of digestion than with the unfractionated $C$. bescii exoproteome. Furthermore, we could recapitulate the activity of the exoproteome by utilizing a combination of only $\mathrm{CbCel9A} / \mathrm{Cel} 48 \mathrm{~A}$ and two of the other enzymes such as $\mathrm{CbCel9B/Man5A}$ and $C b X y n 10 \mathrm{~A} / \mathrm{Cel} 48 \mathrm{~B}$ or $\mathrm{CbCel9B/}$ Man5A and $C b \operatorname{Man} 5 \mathrm{~B} / \mathrm{Cel} 44 \mathrm{~A}$. Given the lack of mannan in the APCS substrate used one might expect to see even larger improvements in digestion on mannan rich substrates such as softwoods which are likely to be present in caldiphilic hot springs. The high extent of glucan and xylan conversion achieved by only three or four gene products suggests a genetically tractable enzyme cassette for conferring cellulolytic ability to high titer CBP microorganisms and for generally reducing the complexity of enzyme preparations in industry.

\section{Methods}

\section{Strains, media, and culture conditions}

Caldicellulosiruptor bescii strains and plasmids used in this study to express four kinds of multi-domain cellulases (Cbes_1867, Cbes_1857, Cbes_1859, and Cbes_1865) are listed in Additional file 1: Table S1. All C. bescii strains were grown anaerobically at $65^{\circ} \mathrm{C}$ in liquid or on solid surface in low osmolarity defined (LOD) medium [26], with maltose or cellobiose $(0.5 \% \mathrm{w} / \mathrm{v})$ as the carbon source, final pH 6.8, for routine growth and transformation experiments [27]. For growth of uracil auxotrophs, LOD medium supplemented with $40 \mu \mathrm{M}$ uracil was used. Liquid cultures were grown at $65{ }^{\circ} \mathrm{C}$ in anaerobic serum bottles having undergone iterative degassing: gassing cycles with nitrogen or argon. E. coli strain DH5 $\alpha$ was used for plasmid DNA construction and preparation using standard techniques as described [28]. E. coli cells were cultured in LB broth supplemented with apramycin $(50 \mu \mathrm{g} / \mathrm{mL})$ and plasmid DNA was isolated using a Qiagen Mini-prep kit (Hilden, Germany). Total DNA from Caldicellulosiruptor strains was extracted using the Quick-gDNA $^{\mathrm{TM}}$ MiniPrep (Zymo) as previously described [23].

\section{Construction of cellulases expression vectors and transformation into $C$. bescii}

Plasmids in this study were generated using Q5 HighFidelity DNA polymerase (New England BioLabs), BamHI and SphI restriction enzymes (New England BioLabs), and Fast-link ${ }^{\mathrm{TM}}$ DNA Ligase (Epicentre Technologies) according to the manufacturer's instructions. Plasmid pJYW011 (Fig. 1b; Additional file 1: Table S1) was constructed by inserting the Cbes_1857 (1478 amino acid; GH10-CBM3 ${ }_{b}$-CBM3 $3_{b}$-GH48) open reading frame into pDCW170 [23], which contains the regulatory region of Cbes_2303 and a Rho-independent transcription terminator. The $7.975 \mathrm{~kb}$ DNA fragment was amplified with primers DC464 containing a BamHI site and DC466 containing a SphI site using pDCW170 as a template. A $4.45 \mathrm{~kb}$ DNA fragment containing the coding sequence of Cbes_1857 was amplified with JY020 containing a BamHI site and JY021 containing a SphI site using $C$. bescii chromosomal DNA as template DNA. These two linear DNA fragments were then digested with BamHI and SphI and ligated to construct pJYW011 (12.41 kb). Plasmid pJYW012 (Fig. 1c; Additional file 1: Table S1) is identical to pJYW011 except that it contains the entire coding sequence of Cbes_1859 (1294 amino acid; GH5-CBM3 ${ }_{b}$-CBM3 ${ }_{b}$-GH44). To make this change, a $3.894 \mathrm{~kb}$ DNA fragment containing the coding sequence of Cbes_1859 was amplified by PCR using primers JY022 (with BamHI site) and JY023 (with SphI site) using C. bescii genomic DNA as template. This fragment ligated with the $7.975 \mathrm{~kb}$ DNA fragment, which was used for the construction of pJYW011, to create pJYW012 (11.86 kb). Plasmid pJYW013 (Fig. 1d; Additional file 1: Table S1) was constructed by inserting the Cbes_1865 (1367 amino acid; $\left.\mathrm{GH} 9-\mathrm{CBM} 3_{\mathrm{c}}-\mathrm{CBM} 3_{\mathrm{b}}-\mathrm{CBM} 3_{\mathrm{b}}-\mathrm{GH} 5\right)$ open reading frame into pDCW173 [23], which contains the regulatory region of Cbes_2303, 6X Histidine tag, and a Rhoindependent transcription terminator. The $7.969 \mathrm{~kb}$ DNA fragment was amplified with primers JY026 and JY027 using pDCW173 as a template. A $4.107 \mathrm{~kb}$ DNA fragment containing the coding sequence of Cbes_1865 was amplified with JY024 and JY025 using C. bescii chromosomal DNA as template DNA. These two linear DNA fragments were ligated via blunt-end ligation to construct pJYW013 (12.01 kb). Primers used for plasmid construction and confirmation are listed in Additional file 1: Table S2. E. coli strain DH5a cells were transformed by electroporation in a 2-mm-gap cuvette at $2.5 \mathrm{~V}$ and transformants were selected for apramycin resistance. The sequences of all plasmids were confirmed by automatic sequencing (Genewiz, NJ USA). All plasmids are available upon request.

To construct C. bescii expression strains JWCB057, JWCB058, and JWCB088, plasmids pJYW011, pJYW012, and pJYW013 were electrotransformed into JWCB029 ( $\triangle$ pyrFA $\triangle l d h:: I S C b e 4$ Acbe1 $\triangle$ celA) cells as previously described [27]. Cultures, electro-pulsed with plasmid DNA $(0.5-1.0 \mu \mathrm{g})$, were recovered in low osmolarity complex (LOC) growth medium [26] at $65^{\circ} \mathrm{C}$. Recovery cultures were transferred to liquid LOD medium without uracil to allow selection of uracil prototrophs. Cultures were plated on solid LOD media to obtain isolated colonies, and total DNA was isolated from transformants. PCR amplification using primers (DCB228 and DCB569) outside the gene cassette on the plasmid was used to 
confirm the presence of the plasmid with the gene of interest intact.

\section{Protein purification}

CbCel9A/Cel48A, CbCel9B/Man5A, CbXyn10A/Cel48B, and $\mathrm{CbMan} 5 \mathrm{~B} / \mathrm{Cel} 44 \mathrm{~A}$ were expressed in $\mathrm{C}$. bescii following the protocol reported earlier [11]. They were purified out of the $C$. bescii exoproteome using a $5 \mathrm{~mL}$ HisTrap fast flow column (GE) and were further purified using a Superdex 26/60 200 PG column in a $20 \mathrm{mM}$ acetate $\mathrm{pH}$ 5.5 buffer containing $100 \mathrm{mM} \mathrm{NaCl}$ and $5 \mathrm{mM} \mathrm{CaCl}_{2}$ similarly to the protocol found in Brunecky et al. [11]. The $C$. bescii exoproteome was prepared following the purification protocol found in Yarbrough et al. [25]. T. maritima $\beta$-D-glucosidase was purchased from Megazyme (Bray, Ireland) and desalted using a Hi-trap 26/10 (GE life sciences) desalting column to remove ammonium sulfate stabilizer in a $20 \mathrm{mM}$ acetate $\mathrm{pH} 5.5$ buffer. Throughout the study, the total protein concentrations were measured by the Bradford method [29].

\section{Effect of $\mathrm{pH}$ and temperature on the activity of $\mathrm{CbCel9A} /$ Cel48A, CbCel9B/Man5A, CbXyn10A/Cel48B, and CbMan5B/Cel44A}

Enzyme activities were measured through sugar release quantification on $10 \mathrm{~g} / \mathrm{L}(1 \% \mathrm{w} / \mathrm{v})$ alkaline peroxide pretreated corn stover (APCS), the compositional analysis of this substrate can be found in Ref. [11]. C. bescii exoproteome and $C b C e l 9 A / C e l 48 \mathrm{~A}$, were loaded at $1 \mathrm{mg} / \mathrm{g}$ glucan and $C b X y n 10 \mathrm{~A} / \mathrm{Cel} 48 \mathrm{~B}, C b \mathrm{Cel} 9 \mathrm{~B} / \mathrm{Man} 5 \mathrm{~A}$, and CbMan5B/Cel44A were loaded at $5 \mathrm{mg} / \mathrm{g}$ glucan to carry out hydrolysis overnight at various temperatures and $\mathrm{pH}$ to determine the optimum conditions for enzyme function. The reaction was stopped by centrifugation of the reaction tube, separation of the supernatant containing soluble sugars, addition of 3,5-dinitrosalicylic acid (DNS) at a ratio of $2: 1$, and immediately followed by a $5 \mathrm{~min}$ boiling step. The solution was assayed at $540 \mathrm{~nm}$ to measure the release of reducing sugars from APCS using glucose as a standard [30].

The optimum temperature of each single enzyme and the $C$. bescii exoproteome was determined by incubation of the enzyme/APCS solution in $20 \mathrm{mM}$ SEC buffer ( $\mathrm{pH}$ 5.5) at different temperatures ranging from 70 to $90^{\circ} \mathrm{C}$.

The optimum $\mathrm{pH}$ was determined using identical enzyme and substrate loadings but at a constant temperature of $75^{\circ} \mathrm{C}$. Reactions were conducted in $20 \mathrm{mM} \mathrm{SEC}$ buffers ranging from $\mathrm{pH} 4.0$ to $\mathrm{pH}$ 7.0.

\section{$p N P$ and $A Z C L$ assay}

To rapidly screen a variety of potential activities we assayed the enzymes against both 4-nitrophenol $(p \mathrm{NP})$ and AZCL dyed substrates. The substrates selected were 4-nitrophenyl-b-D-xylopyranoside $(p \mathrm{NP}-\mathrm{X}), \quad 4$-nitrophenyl- $\beta$-D-cellobioside $\quad(p \mathrm{NP}-\mathrm{C})$, 4-nitrophenyl $\quad \beta$-D-glucopyranoside $\quad(p \mathrm{NP}-\mathrm{G})$, 4-nitrophenyl- $\beta$-D-mannopyranoside ( $p$ NP-Man), 4-nitrophenyl- $\beta$-D-galactopyranoside $\quad(p \mathrm{NP}-\mathrm{Gal})$, 4-nitrophenyl- $\beta$-D-maltopyranoside ( $p \mathrm{NP}-\mathrm{mal}), 4$-nitrophenyl-alpha-l-arabinofuranoside ( $p \mathrm{NP}$-arab), and 4-nitrophenyl- $\alpha$-l-rhamnopyranoside ( $p$ NP-rham). AZCL substrates tested include: AZCL-xyloglucan, AZCL-curdlan, AZCL-potato galactan, AZCL-pachyman, AZCL-amylose, AZCL-dextran, AZCL-B-glucan, AZCL wheat arabinoxlyan, AZCL-galactomannan, and AZCL Oatspelt Xylan. PNP assays were performed in 96 well plates at $75^{\circ} \mathrm{C}$, in $50 \mathrm{mM}$ pH 5.5 acetate buffer with $5 \mathrm{mM} \mathrm{CaCl}_{2}$ added, for $30 \mathrm{~min}$ with the noted enzymes at a concentration of $0.5 \mathrm{mg} / \mathrm{mL}$, then quenched and absorbance recorded at $405 \mathrm{~nm}$ using a Spectromax plate reader. AZCL assays were performed in 96 well plates at $75{ }^{\circ} \mathrm{C}$, in $50 \mathrm{mM}$ pH 5.5 acetate buffer with $5 \mathrm{mM} \mathrm{CaCl}_{2}$ added, for $1 \mathrm{~h}$ at a concentration of $0.25 \mathrm{mg} / \mathrm{mL}$. Activity was noted by visual observation of dye release.

\section{Individual enzyme product detection}

Single enzymes were used on alkaline peroxide pretreated corn stover (APCS) at $10 \mathrm{mg} / \mathrm{g}$ glucan for $24 \mathrm{~h}$ at $75{ }^{\circ} \mathrm{C}$. Analysis of samples for cello and xylooligomers was performed on an Acquity Ultra Performance Liquid Chromatography (UPLC) system (Waters Co., Milford, MA) equipped with a TQD Mass Spectrometer (MS) and Evaporative Light Scattering Detector (ELSD). Waters Masslynx 4.1 software version was used to collect and investigate the analytes of interest. The samples were injected at $10 \mu \mathrm{L}$ per run, separated and detected using an UPLC system equipped with a TQD MS and ELSD detector. The chromatography system utilized a Shodex Sugar SZ5532 (Zinc) column (Showa Denko K.K., Japan) at $6 \times 150(\mathrm{~mm}), 6 \mu \mathrm{m}$ particle size, to sufficiently separate the oligomers of interest. The column temperature was maintained at $60{ }^{\circ} \mathrm{C}$, the buffers used to separate the analytes was $0.1 \%$ formic acid in water (A)/0.1\% formic acid in acetonitrile (B) while keeping samples at $4{ }^{\circ} \mathrm{C}$ within the Acquity Autosampler. The separation was carried out using a gradient program of: $(A)=20 \%$ and $(B)=80 \%$ at time $t=0 ;(\mathrm{A})=17 \%$ and $(\mathrm{B})=83 \%$ at $t=9 \mathrm{~min}$; $(\mathrm{A})=30 \%$ and $(\mathrm{B})=70 \%$ at $t=25 \mathrm{~min} ;(\mathrm{A})=40 \%$ and (B) $=60 \%$ at $t=40 \mathrm{~min}$; (A) $=20 \%$ and (B) $=80 \%$ at $t=45 \mathrm{~min}$. The flow rate was held constant at $0.9 \mathrm{~mL} /$ min and each sample was split approximately around 3:1 between the MS and ELSD detectors. The ELSD parameters were set as follows: drift tube temperature was set to $76{ }^{\circ} \mathrm{C}$ and the gain to 10 . The gas pressure was set to $28 \mathrm{psi}$, while the nebulizer mode, heater-cooler, and data channel were disabled. The TQD MS system was setup 
with electrospray under negative mode with a cone voltage of $30 \mathrm{~V}$, capillary voltage at $3000 \mathrm{~V}$, desolvation temperature at $300{ }^{\circ} \mathrm{C}$ and a source temperature of $110{ }^{\circ} \mathrm{C}$. The MS was calibrated and tuned with Sodium Iodide and subsequent samples where scanned from 50 to 2000 amu with a $1 \mathrm{~s}$ scan time.

\section{Biomass solubilization assay}

The alkaline pretreated corn stover (APCS) was from the same batch as reported in Brunecky and co-workers [11]. For the mono-component biomass digestions we utilized a loading of $15 \mathrm{mg} / \mathrm{g}$ glucan loading for all enzymes tested supplemented with beta glucosidase from $T$. maritima (Megazyme) at a loading of $0.5 \mathrm{mg} / \mathrm{g}$ glucan.

The enzyme loadings in binary, ternary, and quaternary mixtures used to mimic the ratios of these CAZymes in the exoproteome as analyzed by proteomic analysis [13] can be found in Additional file 1: Tables S4, S5. The $C$. bescii exoproteome used for this digestion experiment was loaded at $15 \mathrm{mg} / \mathrm{g}$. All digests were supplemented with $0.5 \mathrm{mg} / \mathrm{g}$ glucan Beta glucosidase from $T$. maritima (Megazyme). CelA mix digestions were performed at $75{ }^{\circ} \mathrm{C}$ at $\mathrm{pH}$ 5.5. All digestions were conducted at a total initial solids loading of $1 \%$.

Digestions were run continuously for 5 days with sampling at various time points. Enzymes were inactivated by boiling for $15 \mathrm{~min}$ after which samples were filtered through $0.45 \mu \mathrm{m}$ Acrodisc syringe filters. The released sugars were analyzed by HPLC. Samples were injected at $20 \mu \mathrm{L}$ volume and run on an Agilent $1100 \mathrm{HPLC}$ system equipped with a BioRad Aminex HPX-87H $300 \mathrm{~mm} \times 7.8 \mathrm{~mm}$ column heated to $55^{\circ} \mathrm{C}$. A constant flow of $0.6 \mathrm{~mL} / \mathrm{min}$ was used with $0.1 \mathrm{~N} \mathrm{H}_{2} \mathrm{SO}_{4}$ in water as the mobile phase to give optimal sugar separation. Glucose, xylose, cellobiose and xylobiose were quantified against independent standard curves and converted to anhydrous glucan equivalent and the results are reported as anhydrous glucan converted. All experiments were performed in triplicate and the resulting extents of conversion are shown as percent glucan or xylan converted.

\section{Additional file}

Additional file 1. Additional tables and figures.

\footnotetext{
Authors' contributions

RB helped design the study, performed the PNP, AZCL, and APCS conversion studies. DC designed, cloned, and expressed the proteins. NSS designed, cloned, and expressed the proteins. NH expressed and purified the proteins, conducted the optimal $\mathrm{pH}$, and temperature assays. JFR designed and cloned the proteins. JY designed and cloned the proteins. AM conducted the AP pretreatment and analyzed the data. PP conducted the optimal pH and temperature assays. TVW expressed the proteins. WM analyzed the data from the conversion studies. TS analyzed the data from the conversion studies. JW designed the proteins and helped design the study. MEH helped design the
}

study. YJB designed the study, purified some of the proteins and supervised the work. All authors contributed and wrote the manuscript. All authors read and approved the final manuscript.

\section{Author details}

${ }^{1}$ Biosciences Center, National Renewable Energy Laboratory, 15013 Denver West Parkway, Golden, CO 80401, USA. ${ }^{2}$ Department of Genetics, University of Georgia, Athens, GA 30602, USA. ${ }^{3}$ Development and Training Institute, King Mongkut's University of Technology Thonburi, Bangkok, Thailand.

\section{Acknowledgements}

Funding provided by the BioEnergy Science Center (BESC) and the Center for Bioenergy Innovation (CBI), from the US Department of Energy Bioenergy Research Centers supported by the Office of Biological and Environmental Research in the DOE Office of Science. PP acknowledges the financial support provided by King Mongkut's University of Technology Thonburi through the "KMUTT 55th Anniversary Commemorative Fund" and "Skill Development Grant". The authors also wish to thank Bernard Henrissat for interesting discussions about the naming conventions for the enzymes studied in this manuscript.

\section{Competing interests}

The authors declare that they have no competing interests.

\section{Consent for publication}

Not applicable.

Ethical Approval and Consent to participate

Not applicable.

\section{Publisher's Note}

Springer Nature remains neutral with regard to jurisdictional claims in published maps and institutional affiliations.

Received: 17 October 2017 Accepted: 9 January 2018

Published online: 01 February 2018

\section{References}

1. Yee KL, Rodriguez M Jr, Thompson OA, Fu C, Wang ZY, Davison BH, Mielenz JR. Consolidated bioprocessing of transgenic switchgrass by an engineered and evolved Clostridium thermocellum strain. Biotechnol Biofuels. 2014;7:75.

2. Yee KL, Rodriguez M Jr, Tschaplinski TJ, Engle NL, Martin MZ, Fu C, Wang ZY, Hamilton-Brehm SD, Mielenz JR. Evaluation of the bioconversion of genetically modified switchgrass using simultaneous saccharification and fermentation and a consolidated bioprocessing approach. Biotechnol Biofuels. 2012;5:81.

3. Hobdey SE, Donohoe BS, Brunecky R, Himmel ME, Bomble YJ. New insights into microbial strategies for biomass conversion. In: Himmel $\mathrm{ME}$, editor. Direct microbial conversion of biomass to advanced biofuels. Amsterdam: Elsevier; 2015.

4. Bayer EA, Belaich JP, Shoham Y, Lamed R. The cellulosomes: multienzyme machines for degradation of plant cell wall polysaccharides. Annu Rev Microbiol. 2004;58:521-54.

5. Bayer EA, Shimon LJ, Shoham Y, Lamed R. Cellulosomes-structure and ultrastructure. J Struct Biol. 1998;124:221-34.

6. Payne CM, Knott BC, Mayes HB, Hansson H, Himmel ME, Sandgren M, Stahlberg J, Beckham GT. Fungal cellulases. Chem Rev. 2015;115:1308-448.

7. Reese ET, Siu RG, Levinson HS. The biological degradation of soluble cellulose derivatives and its relationship to the mechanism of cellulose hydrolysis. J Bacteriol. 1950;59:485-97.

8. Bomble YJ, Lin C-Y, Amore A, Wei H, Holwerda EK, Ciesielski PN, Donohoe BS, Decker SR, Lynd LR, Himmel ME. Lignocellulose deconstruction in the biosphere. Curr Opin Chem Biol. 2017;41:61-70.

9. Dam P, Kataeva I, Yang SJ, Zhou F, Yin Y, Chou W, Poole FL 2nd, Westpheling J, Hettich R, Giannone R, Lewis DL, Kelly R, Gilbert HJ, Henrissat 
B, Xu Y, Adams MW. Insights into plant biomass conversion from the genome of the anaerobic thermophilic bacterium Caldicellulosiruptor bescii DSM 6725. Nucleic Acids Res. 2011;39:3240-54.

10. Brunecky R, Alahuhta M, Xu Q, Donohoe BS, Crowley MF, Kataeva IA, Yang SJ, Resch MG, Adams MW, Lunin W, Himmel ME, Bomble YJ. Revealing nature's cellulase diversity: the digestion mechanism of Caldicellulosiruptor bescii CelA. Science. 2013;342:1513-6.

11. Brunecky R, Donohoe BS, Yarbrough JM, Mittal A, Scott BR, Ding H, Taylor li LE, Russell JF, Chung D, Westpheling J, Teter SA, Himmel ME, Bomble YJ. The multi domain Caldicellulosiruptor bescii CelA cellulase excels at the hydrolysis of crystalline cellulose. Sci Rep. 2017;7:9622.

12. Young J, Chung D, Bomble YJ, Himmel ME, Westpheling J. Deletion of Caldicellulosiruptor bescii CelA reveals its crucial role in the deconstruction of lignocellulosic biomass. Biotechnol Biofuels. 2014;7:142.

13. Lochner A, Giannone RJ, Rodriguez M Jr, Shah MB, Mielenz JR, Keller M, Antranikian G, Graham DE, Hettich RL. Use of label-free quantitative proteomics to distinguish the secreted cellulolytic systems of Caldicellulosiruptor bescii and Caldicellulosiruptor obsidiansis. Appl Environ Microbiol. 2011;77:4042-54.

14. Blumer-Schuette SE, Kataeva I, Westpheling J, Adams MW, Kelly RM. Extremely thermophilic microorganisms for biomass conversion: status and prospects. Curr Opin Biotechnol. 2008;19:210-7.

15. Wang R, Gong L, Xue X, Qin X, Ma R, Luo H, Zhang Y, Yao B, Su X. Identification of the C-terminal GH5 domain from CbCel9B/Man5A as the first glycoside hydrolase with thermal activation property from a multimodular bifunctional enzyme. PLoS ONE. 2016;11:e0156802.

16. Olson DG, Sparling R, Lynd LR. Ethanol production by engineered thermophiles. Curr Opin Biotechnol. 2015;33:130-41.

17. Turner P, Mamo G, Karlsson EN. Potential and utilization of thermophiles and thermostable enzymes in biorefining. Microb Cell Fact. 2007;6:9.

18. Zeldes BM, Keller MW, Loder AJ, Straub CT, Adams MW, Kelly RM. Extremely thermophilic microorganisms as metabolic engineering platforms for production of fuels and industrial chemicals. Front Microbiol. 2015;6:1209.

19. Su X, Mackie RI, Cann IK. Biochemical and mutational analyses of a multidomain cellulase/mannanase from Caldicellulosiruptor bescii. Appl Environ Microbiol. 2012;78:2230-40.

20. Xue X, Wang R, Tu T, Shi P, Ma R, Luo H, Yao B, Su X. The N-terminal GH10 domain of a multimodular protein from Caldicellulosiruptor bescii is a versatile xylanase/beta-glucanase that can degrade crystalline cellulose. Appl Environ Microbiol. 2015;81:3823-33.
21. Ye L, Su X, Schmitz GE, Moon YH, Zhang J, Mackie Rl, Cann IK. Molecular and biochemical analyses of the GH44 module of CbMan5B/Cel44A, a bifunctional enzyme from the hyperthermophilic bacterium Caldicellulosiruptor bescii. Appl Environ Microbiol. 2012;78:7048-59.

22. Yi Z, Su X, Revindran V, Mackie Rl, Cann I. Molecular and biochemical analyses of CbCel9A/Cel48A, a highly secreted multi-modular cellulase by Caldicellulosiruptor bescii during growth on crystalline cellulose. PLoS ONE. 2013;8:e84172.

23. Chung D, Young J, Bomble YJ, Vander Wall TA, Groom J, Himmel ME, Westpheling J. Homologous expression of the Caldicellulosiruptor bescii CelA reveals that the extracellular protein is glycosylated. PLOS ONE. 2015;10:e0119508.

24. Chung D, Young J, Cha M, Brunecky R, Bomble YJ, Himmel ME, Westpheling J. Expression of the Acidothermus cellulolyticus E1 endoglucanase in Caldicellulosiruptor bescii enhances its ability to deconstruct crystalline cellulose. Biotechnol Biofuels. 2015;8:113.

25. Yarbrough JM, Zhang R, Mittal A, Vander Wall T, Bomble YJ, Decker SR, Himmel ME, Ciesielski PN. Multifunctional cellulolytic enzymes outperform processive fungal cellulases for coproduction of nanocellulose and biofuels. ACS Nano. 2017;11:3101-9.

26. Farkas J, Chung D, Cha M, Copeland J, Grayeski P, Westpheling J. Improved growth media and culture techniques for genetic analysis and assessment of biomass utilization by Caldicellulosiruptor bescii. J Ind Microbiol Biotechnol. 2013;40:41-9.

27. Chung D, Cha M, Farkas J, Westpheling J. Construction of a stable replicating shuttle vector for Caldicellulosiruptor species: use for extending genetic methodologies to other members of this genus. PLOS ONE. 2013;8:e62881.

28. Sambrook J, Russell D, editors. Molecular cloning: a laboratory manual. New York: Cold Spring Harbor Laboratory Press; 2001.

29. Zor T, Selinger Z. Linearization of the Bradford protein assay increases its sensitivity: theoretical and experimental studies. Anal Biochem. 1996;236:302-8.

30. Miller GL. Use of dinitrosalicylic acid reagent for determination of reducing sugar. Anal Chem. 1959;31:426-8.

\section{Submit your next manuscript to BioMed Central and we will help you at every step:}

- We accept pre-submission inquiries

- Our selector tool helps you to find the most relevant journal

- We provide round the clock customer support

- Convenient online submission

- Thorough peer review

- Inclusion in PubMed and all major indexing services

- Maximum visibility for your research

Submit your manuscript at www.biomedcentral.com/submit
() Biomed Central 